\title{
The Medical Research Council.*
}

$\mathrm{T}$ the fifteenth annual report of the Medical Research Council, the opportunity is taken to review the progress of the past five years as well as the work of the year 1928-29. Certain changes in the composition of the Council occurred during the year: the late Lord Balfour resigned the chairmanship and was succeeded by Lord D'Abernon : Sir Charles Trevelyan, Prof. E. P. Cathcart, and Sir Charles Sherrington retired, and were succeeded by Major A. G. Church, Prof. J. J. R. Macleod, and Mr. W. Trotter.

The financial resources of the Council have again been augmented by donations from private benefactors and various public bodies: at the same time, grants have been made to numerous workers at university and other centres of research and the laboratory facilities provided by these authorities have indirectly extended the resources of the Council. In addition to appointing annually suitable workers to the Rockefeller Travelling Medical Fellowships, the Council during the past year has received a donation from Mrs. Odo Cross for the endowment of research fellowships for the study of tuberculosis.

The title of the Industrial Fatigue Research Board has been changed to the Industrial Health Research Board, since its investigations are now chiefly directed towards problems other than fatigue as such. Among other changes in the constitution of the Board, Lord D'Abernon has retired from the chairmanship and has been succeeded by Sir Arnold Wilson.

The report points out that at no time has a capital grant been made to the Council for the provision of laboratories and equipment: the National Institute and the field Laboratories have been acquired and equipped out of income. The former was bought in 1914 out of monies derived from non-expended income in the first year of work before any awarded grants became effective: during the War, the building reverted to its original use as a hospital ; after the War, scientific equipment for the Institute and a freehold site of nearly 40 acres at Mill Hill were acquired out of savings accumulated during the War. Further equipment has been gradually provided out of income, a laboratory building at the farm from a bequest by the late Miss $\mathrm{O}$. H. Stubber, and during the past year a much needed extension to the Institute from a bequest by the late Lord Justice Ronan. The latter was designed to give the highest standard of hygienic conditions for the keeping of experimental animals : its completion brings the National Institute as a whole, including the Farm Laboratories, to a stage of development which may be expected to provide all the main requirements for the research work centralised here for many years. With the increase in accommodation provided by this extension, it has now been possible to remove the unsightly huts from the grounds of the Institute.

* Committee of the Privy Council for Medical Research. Report of the Medical Research Council for the year 1928-29. (London: H.M. Stationery Office, 1930.) Price $3 s$. net.
One of the most important functions of the Council is the establishment, maintenance, and distribution of standards for certain remedies, the activity of which can only be measured by biological methods. This work involves the preparation of stable standards and the determination of suitable methods of biological assay, as well as the checking of the activity of new preparations of the standard, especially in terms of an international standard, where such exists. The following national standards are required to be kept at the Institute under the Therapeutic Substances Act 1927: diphtheria antitoxin, tetanus antitoxin, antidysentery serum (Shiga), tuberculin, insulin, pituitary posterior lobe, arsenobenzene, novarsenobenzene, and sulpharsenobenzene. All these are based on the international standards, of which those for tuberculin and insulin were actually prepared at the Institute. The international standards now held there for maintenance and general distribution are those of insulin, sulpharsenobenzene, digitalis, and ouäbain. National standards for the two latter are available for distribution when any authority shall require them. The only commercial products which are now regularly tested at the Institute before issue are the drugs of the arsenobenzene group, but samples of the other scheduled substances prepared by the manufacturers and assayed in terms of the standard are periodically tested to see that they fulfil the specified requirements of potency, sterility, etc.

The fact that most of the research work supported by the Council is conducted in the laboratory raises the question, Is there a science of experimental medicine, of which the material for study is the human patient? Clinical research can only rarely be carried out by a practising physician : his work is to diagnose the condition from which the patient is suffering and to treat it, for which he must have a wide knowledge and experience of disease. The advancement of scientific knowledge cannot be his primary object. The clinical research worker, on the other hand, can devote his attention to one particular disease or group of diseases, and need not maintain his knowledge and skill at concert pitch over the whole clinical field. He must tend to ignore the individual patient and study the disease process as such by experimental methods, whether at the bedside or in the laboratory. Again, it is clear that the teaching of general medicine is incompatible with a whole-time devotion to the study of one small corner of this field. It is for this reason that the clinical ' units' set up in certain teaching hospitals have been unable to carry out much research work although they have served as excellent centres for the teaching of clinical medicine.

Fifteen years ago the Council set up a clinical 'research unit' at University College Hospital, London, appointing Dr. (now Sir) Thomas Lewis as whole-time director and providing adequate personnel and facilities for his work. The success of this experiment answers the question asked 
above : there is a science of experimental medicine. The work of Sir Thomas Lewis and his collaborators on the heart and vascular system, its disorders and their treatment, has constituted the central stream of progress made in these subjects during the past decade. For similar advances in other directions it is essential to recruit clinical research workers, but men will not be attracted without the possibility of some definite post in clinical research being available to them in the future, which is not the case at present. The Council therefore proposes to increase the number of clinical workers upon its permanent staff as soon as suitablytrained candidates who have shown their aptitude for this type of research are available. Meanwhile, the Council is prepared to encourage young workers to test themselves in this branch of medical re. search with the view of its becoming their lifework.

The vascular response of the skin to injury has been further investigated during the year. The vessels in the frog's tongue react to injury in the same way as those of the human skin, but do not respond to histamine. A substance, probably a base of the histidine-arginine series can, however, be extracted from frog's skin which will reproduce the vascular reactions of injury not only in the frog's tongue, but also in the human skin (Grant and Jones). This result confirms the previous conclusion that the reaction to injury consists essentially in the liberation from the cells of the skin of histamine or some similar substance. Similarly, the demonstration that acetylcholine can be isolated from the spleen is evidence in favour of its actual liberation in the tissues following certain kinds of nervous action, when the results of such nervous stimulus can be duplicated by the injection of acetylcholine (Dale and Dudley).

In this review it is impossible to refer to more than one or two of the other researches which have been carried out by members of the scientific staff of the Council or by independent workers helped by grants-in-aid: abstracts of these researches, together with references to published papers, are given in the report. Work on virus diseases has been continued: the difficulty of making rapid progress is due to the fact that they cannot yet be grown on artificial media, although some will grow in vitro in the presence of a piece of surviving tissue. The present position with regard to viruses is rather like that facing bacteriologists fifty years ago before adequate methods of microscopic study and cultivation had been worked out. More progress has been made in the devising of methods of immunising animals to these diseases, and it is now possible to immunise dogs to distemper, fowls to fowl plague, and monkeys to yellow fever.

Research on chemotherapeutic agents is being actively pursued: certain aromatic amides containing arsenic have a pronounced curative action in some types of trypanosomiasis, as well as some new styryl compounds : the latter are being tested against trypanosomiasis of cattle in Tanganyika Territory.

Finally, among other subjects referred to in the report may be mentioned work on cancer and radium, anæsthetics, the vitamins, and the physiological actions of different types of light.

\section{The Deutsches Museum, Munich.}

THE Royal Commission on National Museums 1 and Galleries in its Final Report, of which, as a whole, we had something to say in our issue of Feb. 1 (p. 153), deals with individual institutions. We are particularly interested in those which are wholly or partly of a scientific character, and we notice that the Commissioners in dealing with the Science Museum direct pointed attention to the Deutsches Museum von Meisterwerken der Naturwissenschaft und Technik, to give it its full title, " not only because it is in itself a remarkable example of how a modern Museum can be made a great instrument of technical as well as of popular instruction, but because it is a symbol of national efficiency. It reveals the intense concentration in the Germany of to-day on the scientific means of industrial progress, a concentration which we believe has its sharp significance for this country." We are pleased, by the way, to see that the Commissioners commend to the nation the scientific attitude of mind, for it is one that we try year in and year out in these columns to inculcate.

Perhaps, then, we can scarcely do greater service to our readers than to place before them a brief account of the Deutsches Museum. Its aim is stated succinctly and correctly in the words of the Report : to illustrate " the development of research and discovery of every age and of all countries, an Institution in which the results of scientific research and experiment should be fully shown. . . . But beyond this another purpose has been kept in view. The Museum is to be a great instrument for the education of the visitor. He must not only be informed by studying the exhibits as to the growth and progress of a subject, but as far as possible he must be put into a position to realize and verify, through experiments performed by himself, the steps by which the progress has been achieved.' Such is the example held up to us for emulation.

A short account of the Museum was published in NATURE in 1925 (Vol. 115, 611), when the Museum was about to be formally opened, and it is unnecessary, therefore, to repeat the history beyond saying that the institution, contrary to what one might expect in Germany, is neither State owned nor State governed. It owes its inception and management up to the present to Dr. Ing. Oskar von Miller, a distinguished electrical power engineer, and it is an open secret that the idea of forming a museum of this kind was implanted in his mind when, as a young man, he visited the Loan Collection of Scientific Apparatus at South Kensington in 1876. He pondered the idea for more than a quarter of a century until he felt able to put his

No. 3156, VoL. 125] 